\title{
Immunometric Antibody Sandwich Enzyme-Linked Immunosorbent Assay
}

\author{
Thomas O. Kohl and Carl A. Ascoli
}

The antibody sandwich enzyme-linked immunosorbent assay (ELISA) is the most commonly used assay for rapid and accurate detection of antigens. It displays greater sensitivity compared with the indirect ELISA and can be used to determine absolute antigen concentrations in unknown samples provided purified antigen standards are available, although it requires the use of two different antibodies. Briefly, wells are coated with antigen-specific capture antibody then incubated with samples containing unknown antigen. Washing removes unbound antigen and exogenous sample protein before incubation with a second antigen-specific detection antibody, washing, and reincubation with a reporter-labeled tertiary antibody. After tertiary antibody is washed off, substrate is added and hydrolysis is measured spectrophotometrically. The signal intensity is directly proportional to the concentration of the antigen in the test sample.

It is essential that you consult the appropriate Material Safety Data Sheets and your institution's Environmental Health and Safety Office for proper handling of equipment and hazardous materials used in this protocol.

RECIPES: Please see the end of this protocol for recipes indicated by $<R>$. Additional recipes can be found online at http://cshprotocols.cshlp.org/site/recipes.

Reagents

3,3',5,5'-tetramethylbenzidine (TMB) (Rockland Immunochemicals, \#TMBE-1000) (for horseradish peroxidase [HRP]-based assays)

Antibodies of known concentration for antigen-specific capture and detection

These can be polyclonal/monoclonal, monoclonal/monoclonal, or monoclonal/polyclonal antibody combinations (Rabin et al. 1992; Hornbeck et al. 2001). Addition of a reporter-labeled detection antibody (which eliminates the need for a tertiary antibody) converts this assay into a direct sandwich ELISA (Fig. 1).

Antibody, enzyme-labeled antihost, and dilution buffer (e.g., Rockland Immunochemicals \#MB-061-

100 or \#MB-076-0100)

Antigen at an unknown concentration

Blocking buffer (3\% [w/v] fish gel [Sigma-Aldrich, \#G7765] in PBS or TBS)

Carbonate buffer for immunoassays $<\mathrm{R}>$ (optional; see Step 1)

Detection-antibody diluent (1\% [v/v] fish gel in PBS or TBS)

para-Nitrophenyl phosphate (pNPP) (Rockland Immunochemicals, \#NPP-10) (for alkaline phosphatase $[\mathrm{AP}]$-based assays)

From the Antibodies collection, edited by Edward A. Greenfield.

(C) 2017 Cold Spring Harbor Laboratory Press

Cite this protocol as Cold Spring Harb Protoc; doi:10.1101/pdb.prot093716 


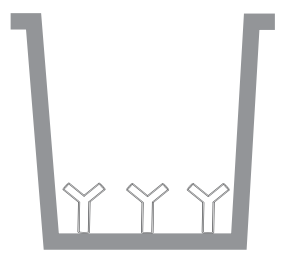

Immobilized capture antibody

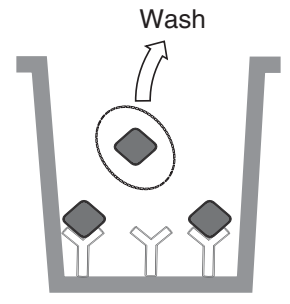

Addition of antigen

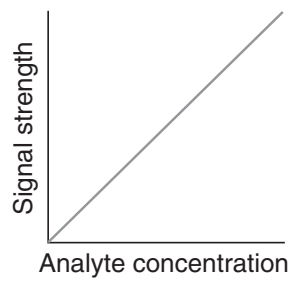

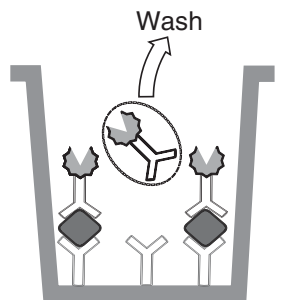

Labeled secondary antibody

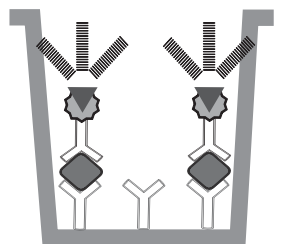

Substrate addition, signal detection, and quantification

Signal strength is directly proportional to analyte concentration.

FIGURE 1. Direct sandwich ELISA for the chemiluminescent detection of soluble antigen.

Phosphate-buffered saline (PBS) for immunoassays (pH 7.4) $<\mathrm{R}>$

Stop solution (1 M HCl) (for HRP-based assays only; see Step 14)

Tris-buffered saline (TBS) for immunoassays $<\mathrm{R}>$ (optional; see Step 1)

Wash buffer with detergent (PBS or TBS containing 0.05\% [v/v] Tween 20)

Equipment

Microplate reader (Bio-Rad, Model \#680) with Microplate Manager Software (5.2.1) or equivalent

Microplate sealing tape, polyester, nonsterile (Corning, \#4612 or equivalent)

Microtiter plates (flat bottom, 96-well, $0.3 \mathrm{~mL}$ per well) with appropriate surface chemistry (e.g.,

Immulon 4 HBX; Thermo Scientific, \#3855 or equivalent)

Multichannel pipettes (eight- or 12-channel) (Costar \#4888 or equivalent)

Plate washer (Dynex Ultrawash PLUS or equivalent)

Reagent reservoirs (VWR, \#12577-027 or equivalent)

1. Dilute the capture antibody to a final concentration of $1 \mu \mathrm{g} / \mathrm{mL}$ in PBS, TBS, or a carbonate buffer. Coat a microtiter plate by pipetting $100 \mu \mathrm{L}$ of diluted antibody into individual wells.

For HRP conjugates, use PBS or carbonate buffer. For AP conjugates, use TBS. Dilution of the monoclonal or polyclonal capture antibody to a final concentration of $1 \mu \mathrm{g} / \mathrm{mL}$ serves as an indicator only. It is best to titrate the antibody against the standard antigen by indirect ELISA using the checkerboard titration format (see Protocol: Indirect Immunometric ELISA [Kohl and Ascoli 2017]). The final antibody working concentration should be adjusted to the lowest concentration that results in maximum signal strength.

2. Cover the plate with a lid or plastic adhesive. Incubate for $1 \mathrm{~h}$ at room temperature or overnight at $2^{\circ} \mathrm{C}-8^{\circ} \mathrm{C}$.

3. Using a plate washer, aspirate the coating solution. Wash the plate three times by filling each well with $300 \mu \mathrm{L}$ of wash buffer containing detergent. Remove retained liquid by patting the plate on a paper towel.

4. Add $200 \mu \mathrm{L}$ of $3 \%(\mathrm{v} / \mathrm{v})$ fish gel in PBS or TBS blocking buffer to block the remaining proteinbinding sites. Incubate for $1 \mathrm{~h}$ at room temperature or $30 \mathrm{~min}$ at $37^{\circ} \mathrm{C}$.

5. Aspirate the blocking solution using the plate washer. Wash the plate as described in Step 3. 


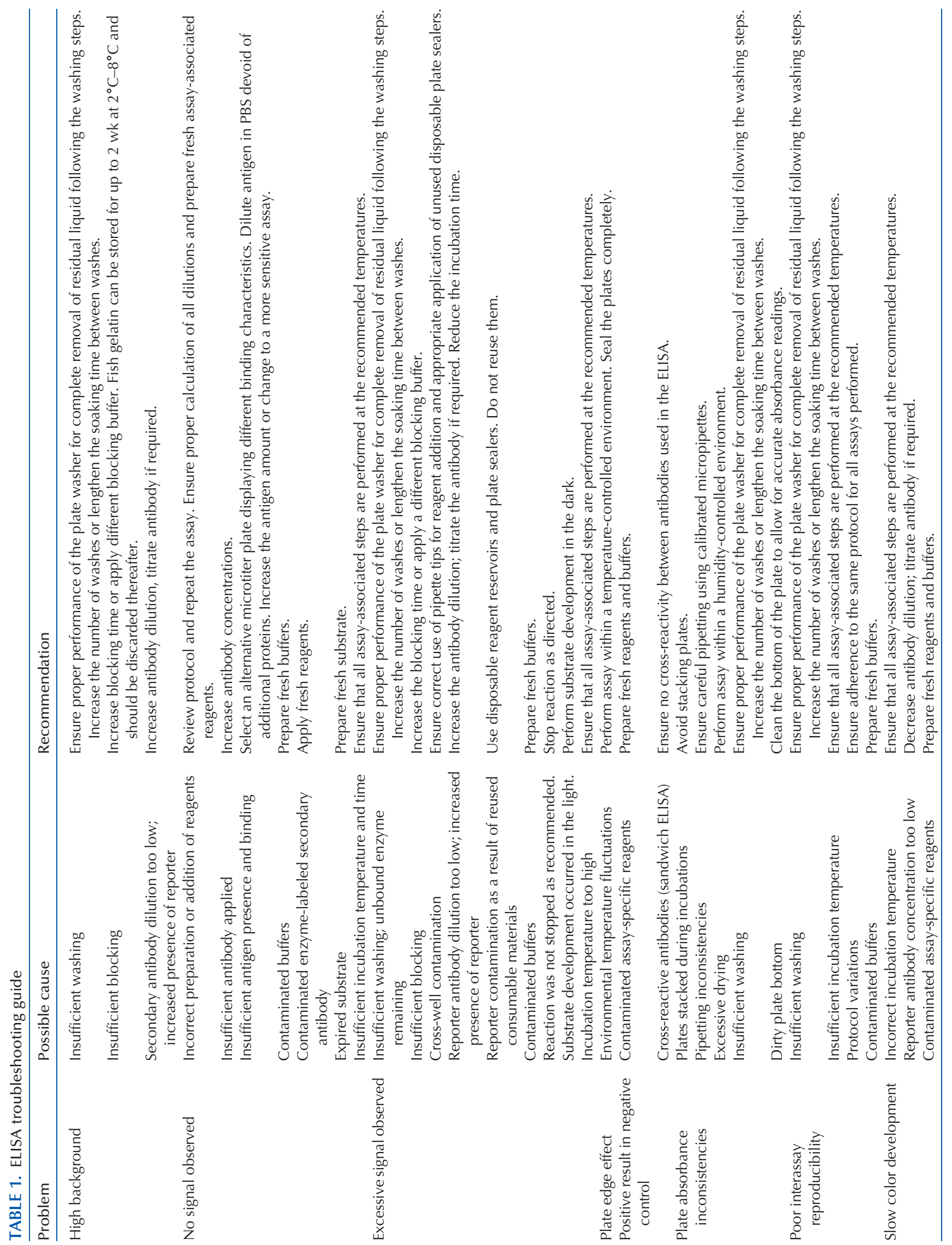


6. Prepare a standard antigen dilution at a recommended concentration of $1 \mu \mathrm{g} / \mathrm{mL}$ in PBS. Add $100 \mu \mathrm{L}$ to selected wells in Column 1. Titrate twofold or another serial dilution across the length of the plate. Incubate for $1 \mathrm{~h}$ at room temperature. Antigen blanks and assay blanks do not receive any antigen solution.

For an accurate determination of antigen concentration in unknown samples, the standard antigen dilution series needs to cover the dynamic range of the assay. Defined as the range in which the sensitivity of the immunoassay is determined by the interplay between antigen concentration and signal strength, a derived standard curve permits accurate determination of antigen concentrations within unknown samples. The dynamic range of an assay is antigen dependent and typically spans the femtogram-to-microgram detection range.

7. Add $100 \mu \mathrm{L}$ of test antigen to selected wells in Column 1. Titrate the test antigen by twofold or another serial dilution across the length of the plate. Incubate for $1 \mathrm{~h}$ at room temperature.

Given the unknown antigen content of test samples, it is best to assay two different, preferentially overlapping, serial dilutions of the test antigen to ensure that a dilution series falls within the assay's dynamic range and allows for accurate measurement. Assay performance over several plates needs to include the standard antigen dilution series as well as assay controls on every plate. Individual samples should be run in duplicate or triplicate for accurate quantification.

8. Aspirate the antigen solution using the plate washer. Wash the plate as described in Step 3.

9. Dilute the detection antibody to a final concentration of $1 \mu \mathrm{g} / \mathrm{mL}$ in $1 \%(\mathrm{v} / \mathrm{v}$ ) fish gel in PBS. Pipette $100 \mu \mathrm{L}$ of the detection antibody into each well across the plate, including the antigen blank control wells. Incubate the plates for $1 \mathrm{~h}$ at room temperature.

Dilution of the monoclonal or polyclonal detection antibody to a final concentration of $1 \mu \mathrm{g} / \mathrm{mL}$ serves as an indicator only. It is best to titrate the antibody against the standard antigen by indirect ELISA using the checkerboard titration format (see Fig. 1 of Protocol: Indirect Immunometric ELISA [Kohl and Ascoli 2017]). The final antibody working concentration should be adjusted to the lowest concentration that results in maximum signal strength.

10. Aspirate the detection antibody solution using the plate washer as described in Step 3.

11. Prepare enzyme-labeled antihost antibody at a recommended dilution of 1:20,000 using the dilution buffer provided with the antibody. Add $100 \mu \mathrm{L}$ to each well including the assay control wells. Incubate for $30 \mathrm{~min}$ at $37^{\circ} \mathrm{C}$.

A 1:20,000 dilution of the reporter-labeled antibody is a recommendation only and is dependent on the concentration of the reporter antibody. It is best to titrate the antibody by indirect ELISA using the checkerboard titration format to determine the optimal working concentration. When using self-type antibodies (mouse-derived monoclonal/monoclonal or rabbit-derived polyclonal/polyclonal) in the sandwich ELISA, the detection antibody must be biotinylated or directly labeled to prevent nonspecific cross-reactivity of the reporter-labeled antibody with both the capture and detection antibodies. It is best to use reporter-labeled antibodies in a sandwich ELISA in which the detection and capture antibodies are derived from different species. This guarantees that nonspecific cross-reactivity will not be observed on addition of the tertiary antibody.

12. Using the plate washer, aspirate the reporter-labeled tertiary antibody solution. Wash the plate as described in Step 3.

13. Prepare or equilibrate the substrate solution (TMB for HRP or pNPP for AP) to room temperature. Add $100 \mu \mathrm{L}$ to each well. Incubate the enzyme-based reactions for $30 \mathrm{~min}$ at room temperature in the dark.

Avoid introducing air bubbles when adding substrate to the wells, because these will affect the absorbance readings.

14. Stop the HRP reaction by adding $100 \mu \mathrm{L}$ of $1 \mathrm{M} \mathrm{HCl}$ per well. Alkaline phosphatase-based substrate development does not require a stopping reagent.

For further quantification of low-level reactions, skip Step 14 and perform plate measurements at set time intervals.

15. Read the plates on a microplate reader set to $405 \mathrm{~nm}$ for AP-based and $450 \mathrm{~nm}$ for HRP-based substrate development. 
16. Prepare a standard curve from the data by plotting standard antigen concentration on the $x$-axis versus absorbance on the $y$-axis. Use this standard curve to determine the antigen concentration of unknown test samples.

The results from ELISAs using chemiluminescent or fluorescent reporters will be in relative light units (RLUS) instead of absorbance in the standard curve. Standard curves are only required to determine the amount of antigen in test samples accurately; they are redundant for qualitative answers.

Please see Table 1 for a detailed troubleshooting guide.

\section{DISCUSSION}

The sensitivity of the sandwich ELISA depends on: (1) the number of molecules of capture antibody immobilized on the well's surface; (2) the avidity of the capture antibody for the antigen; (3) the avidity of the detection antibody for the antigen; and (4) the specific activity of the detection antibody in the ELISA. When using monoclonal/monoclonal or polyclonal/polyclonal combinations, a subset of the antibody must be biotinylated or directly labeled with a reporter of choice to detect the antigen. Furthermore, when using two monoclonal antibodies, they must recognize discrete epitopes on the antigen under investigation.

\section{Optimizing Pairwise Antibody Concentrations}

In addition to being suitable for the detection or quantification of different antigens and antibodies, the sandwich ELISA is essential for identifying suitable antibody pairs for assay development. Here we provide an example that uses the sandwich ELISA to determine the most suitable antibody pair from three monoclonal antibodies—designated $A b_{1}, A b_{2}$, and $\mathrm{Ab}_{3}$-raised against the same antigen.

A checkerboard titration of $\mathrm{Ab}_{1}$ against purified antigen is shown in Table 2. Plates were coated with twofold serially diluted antigen starting at $1 \mu \mathrm{g} / \mathrm{mL}$ or $100 \mathrm{ng}$ per well (rows A-H). $\mathrm{Ab}_{1}$ was added to the wells in Column 1 at $1 \mu \mathrm{g} / \mathrm{mL}$ or $100 \mathrm{ng}$ per well. $A b_{1}$ was twofold serially diluted and added to the remaining columns across the plate (Columns 2-10). Similar checkerboard titrations of $\mathrm{Ab}_{2}$ and $\mathrm{Ab}_{3}$ were performed. For all three monoclonal antibodies, the optimal working concentration was 0.5 $\mu \mathrm{g} / \mathrm{mL}$.

Next, these were paired in sandwich ELISAs to determine the best antibody pair to use. To determine the best antibody combination, capture antibody and antigen concentrations were kept constant, while the detection antibody was titrated across the plate in the initial assay (Fig. 2A). Similarly, all possible antibody pairs were analyzed by titration of the antigen across the plate (Fig. 2B). Out of the six possible pairwise combinations, the pairing of $\mathrm{Ab}_{3}$ as capture antibody $\left(c A b_{3}\right)$ and $A b_{1}$ as detection antibody $\left(\mathrm{dAb}_{1}\right)$ resulted in the best detection specificity within the assay.

TABLE 2. Checkerboard titration of antigen and antibody by serial dilution

\begin{tabular}{|c|c|c|c|c|c|c|c|c|c|c|c|c|}
\hline \multirow[b]{2}{*}{ Antigen (ng per well) } & \multicolumn{12}{|c|}{ Antibody 1 (ng per well) } \\
\hline & 100 & 50 & 25 & 12.5 & 6.25 & 3.125 & 1.563 & 0.781 & 0.391 & 0.195 & $2^{\prime}-\mathrm{Ab}$ only & Substrate only \\
\hline 100 & 4.000 & 4.000 & 4.000 & 4.000 & 4.000 & 4.000 & 4.000 & 4.000 & 4.000 & 4.000 & 0.053 & 0.041 \\
\hline 50 & 4.000 & 4.000 & 4.000 & 4.000 & 4.000 & 4.000 & 4.000 & 4.000 & 4.000 & 4.000 & 0.079 & 0.043 \\
\hline 25 & 4.000 & 4.000 & 4.000 & 4.000 & 4.000 & 4.000 & 4.000 & 4.000 & 4.000 & 4.000 & 0.055 & 0.040 \\
\hline 12.5 & 4.000 & 4.000 & 4.000 & 4.000 & 4.000 & 4.000 & 4.000 & 4.000 & 4.000 & 4.000 & 0.103 & 0.041 \\
\hline 6.25 & 4.000 & 4.000 & 4.000 & 4.000 & 4.000 & 4.000 & 4.000 & 4.000 & 4.000 & 3.465 & 0.123 & 0.049 \\
\hline 3.125 & 4.000 & 4.000 & 4.000 & 4.000 & 4.000 & 4.000 & 4.000 & 3.416 & 2.970 & 1.943 & 0.083 & 0.046 \\
\hline 1.5625 & 2.497 & 3.031 & 2.663 & 2.678 & 2.639 & 2.395 & 2.444 & 1.793 & 1.627 & 1.113 & 0.058 & 0.048 \\
\hline 0.78125 & 1.168 & 1.393 & 1.282 & 1.103 & 1.137 & 1.048 & 0.964 & 0.706 & 0.562 & 0.485 & 0.125 & 0.054 \\
\hline
\end{tabular}


A

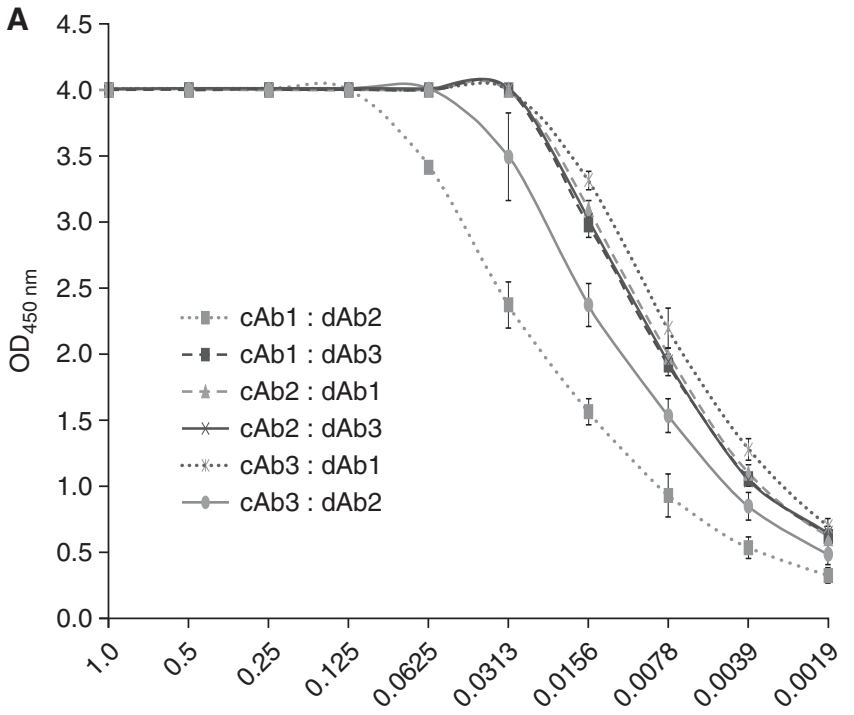

[Detection antibody] (in $\mu \mathrm{g} / \mathrm{mL})$

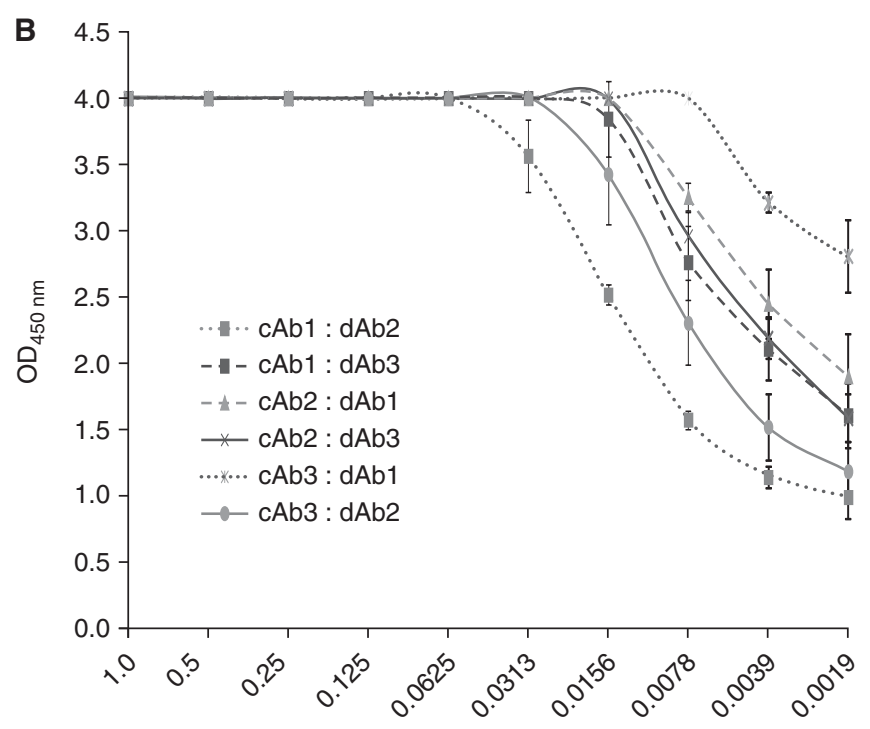

[Antigen] (in $\mu \mathrm{g} / \mathrm{mL}$ )

FIGURE 2. (A) Detection antibody and $(B)$ antigen titration.

The host cell protein (HCP) ELISA is a specialized form of the sandwich ELISA that incorporates polyclonal antibody capable of detecting high- and low-molecular-weight proteins within the complex mixture of a host cell lysate. Development of a HCP ELISA requires that polyclonal antibody is labeled with a reporter of choice. The optimal working concentrations of both unlabeled capture antibody and labeled detection antibody are determined by "scouting," a process in which antibody reactivity is measured against multiple targets within the mixture. Scouting is performed by diluting the HCP as shown in Figure 3. The antibodies are then titrated against the HCP. Establishment of optimal working concentrations for both capture and detection polyclonal antibodies results in the development of a sandwich ELISA in which sensitive detection of multiple antigens is achieved (Fig. 4).

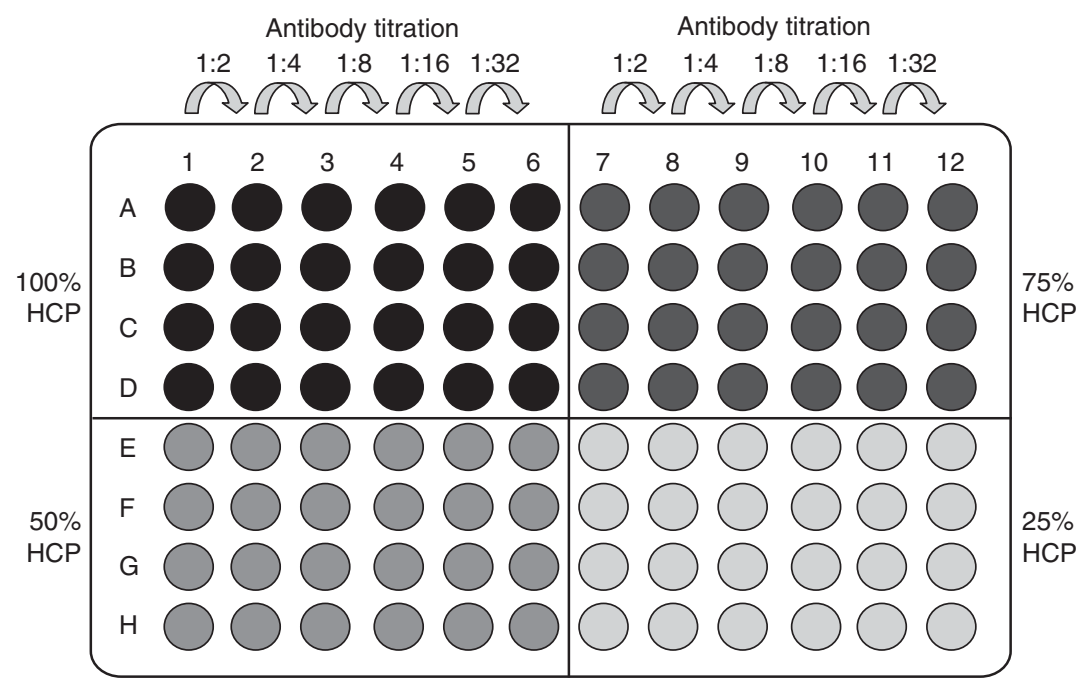

FIGURE 3. Titration of polyclonal antibody against various dilutions of the HCP mixture. 


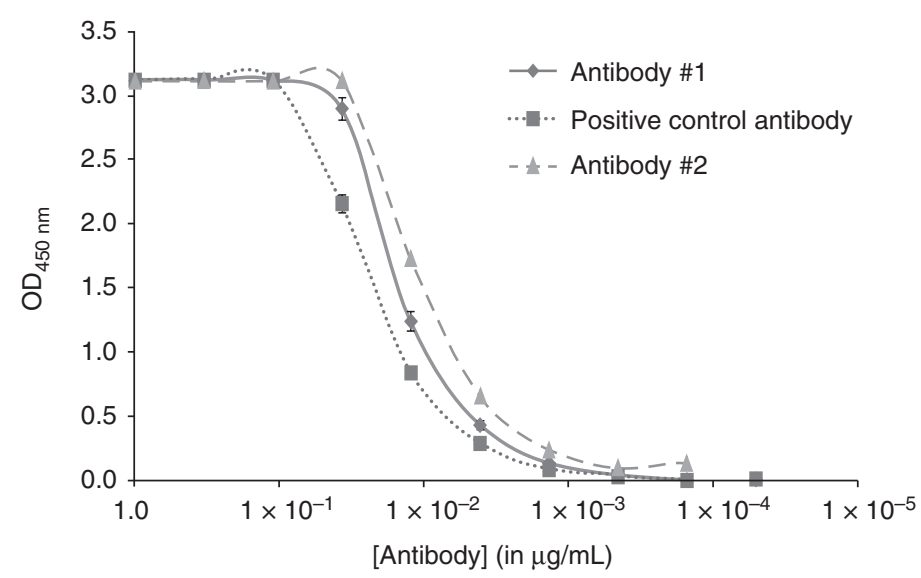

FIGURE 4. Antibody titration across an optimal predetermined HCP range.

\section{ELISpot Assay}

The enzyme-linked immunosorbent spot (ELISpot) assay is based on the sandwich ELISA. Originally developed for the enumeration of antigen-specific antibody-secreting B cells, this assay is now used mainly to enumerate cells within a cell monolayer that produce small cell-signaling molecules. Monoclonal or polyclonal antibodies specific for small cell-signaling molecules are immobilized onto polyvinylidene fluoride or nitrocellulose membranes in microtiter plate wells (Weiss 2012). After blocking, the cells of interest are plated at a predetermined density together with an antigen or mitogen and incubated at $37^{\circ} \mathrm{C}$ in a humidified $\mathrm{CO}_{2}$ incubator. Cell-signaling molecules secreted by antigen/mitogen-activated cells are captured by the membrane-immobilized antigen-specific antibody. The filters are washed to remove cells and tissue culture medium, followed by the addition of antigen-specific reporter-labeled antibody. Again, the filters are washed, and an insoluble/precipitating substrate is added. Substrate hydrolysis results in the formation of a colored end product visible as spots on the filter. Each spot represents an individual cell that has produced small cell-signaling molecules. Spots can be counted and their size measured, providing both qualitative and quantitative information (Slota et al. 2011).

\section{RECIPES}

Carbonate Buffer for Immunoassays

Reagent Amount per $1 \mathrm{~L}$ of solution

$\mathrm{Na}_{2} \mathrm{CO}_{3} \quad 1.59 \mathrm{~g}$

$\mathrm{NaHCO}_{3} 2.93 \mathrm{~g}$

Adjust to $\mathrm{pH} 9.5$ using $1 \mathrm{~N} \mathrm{NaOH}$. Store at ambient temperature.

Phosphate-Buffered Saline (PBS) for Immunoassays ( $\mathrm{pH}$ 7.4)

Reagent Amount per 1 L of solution

$\begin{array}{lr}\mathrm{NaCl} & 8 \mathrm{~g} \\ \mathrm{KCl} & 0.2 \mathrm{~g} \\ \mathrm{Na}_{2} \mathrm{HPO}_{4} & 1.44 \mathrm{~g} \\ \mathrm{KH}_{2} \mathrm{PO}_{4} & 0.24 \mathrm{~g}\end{array}$

Store at ambient temperature. 
Downloaded from http://cshprotocols.cshlp.org/ on April 26, 2023 - Published by

Immunometric Antibody Sandwich ELISA

Tris-Buffered Saline (TBS) for Immunoassays

Reagent

$\mathrm{NaCl}$

$\mathrm{KCl}$

Tris- $\mathrm{HCl}$

Adjust to pH 7.6 using $1 \mathrm{~N} \mathrm{NaOH}$. Store at ambient temperature.
Amount per $1 \mathrm{~L}$ of solution

$8 \mathrm{~g}$

$0.2 \mathrm{~g}$

$3 \mathrm{~g}$

\section{REFERENCES}

Hornbeck P, Winston SE, Fuller SA. 2001. Enzyme-linked immunosorbent assays (ELISA). Curr Protoc Mol Biol Chapter 11: Unit11.2.

Kohl TO, Ascoli CA. 2017. Indirect immunometric ELISA. Cold Spring Harb Protoc doi: 10.1101/pdb.prot093708.

Rabin DU, Palmer-Crocker R, Mierz DV, Yeung KK. 1992. An ELISA sandwich capture assay for recombinant fusion proteins containing glutathione-S-transferase. J Immunol Methods 156: 101-105.
Slota M, Lim J-B, Dang Y, Disis ML. 2011. ELISpot for measuring human immune responses to vaccines. Expert Rev Vaccines 10: 299-306.

Weiss AJ. 2012. Overview of membranes and membrane plates used in research and diagnostic ELISpot assays. Methods Mol Biol 792: 243-256. 


\section{Immunometric Antibody Sandwich Enzyme-Linked Immunosorbent Assay}

Thomas O. Kohl and Carl A. Ascoli

Cold Spring Harb Protoc; doi: 10.1101/pdb.prot093716

\begin{tabular}{rc}
$\begin{array}{r}\text { Email Alerting } \\
\text { Service }\end{array}$ & Receive free email alerts when new articles cite this article - click here. \\
\hline $\begin{array}{c}\text { Subject } \\
\text { Categories }\end{array}$ & $\begin{array}{c}\text { Browse articles on similar topics from Cold Spring Harbor Protocols. } \\
\text { Antibodies (119 articles) } \\
\text { Antibodies, general (289 articles) } \\
\text { Immunoassay (26 articles) }\end{array}$ \\
\hline
\end{tabular}

